Плодоводство и виноградарство Юга России № 64(4), 2020 г.

УДК 634.85:631.524(470.61)

DOI 10.30679/2219-5335-2020-4-64-240-250

РЕЗУЛЬТАТЫ ИЗУЧЕНИЯ
ИНТРОДУЦИРОВАННЫХ
ТЕХНИЧЕСКИХ СОРТОВ
ВИНОГРАДА НА КОЛЛЕКЦИИ
В НИЖНЕМ ПРИДОНЬЕ*

Ганич Валентина Алексеевна канд. с.-х. наук ведущий научный сотрудник лаборатории ампелографии e-mail: ganich1970@yandex.ru

Наумова Людмила Георгиевна канд. с.-х. наук ведущий научный сотрудник лаборатории ампелографии e-mail: LGnaumova@yandex.ru

Всероссийский научно-исследовательский институт виноградарства и виноделия имени Я.И. Потапенко филиал Федерального государственного бюджетного научного учреждения «Федеральный Ростовский аграрный научный центр», Новочеркасск, Россия

Цель исследований - изучение интродуцированных технических сортов винограда различного экологогеографического происхождения; выявление адаптивного, хозяйственного и технологического потенциала образцов в целях отбора генотипов с улучшенными экономически значимыми свойствами в условиях Нижнего Придонья. Изучение сортов проводили в 2017-2019 гг. на Донской ампелографической коллекции имени Я.И. Потапенко (г. Новочеркасск), по общепринятым в виноградарстве методикам и ГОСТам. В результате
UDC 634.85:631.524(470.61)

DOI 10.30679/2219-5335-2020-4-64-240-250

\section{THE RESULTS OF STUDY \\ OF INTRODUCED TECHNICAL GRAPEVINE VARIETIES ON THE COLLECTION IN THE LOWER DON REGION*}

\author{
Ganich Valentina Alekseyevna \\ Cand. Agr. Sci. \\ Leading Research Associate \\ of Ampelographic Laboratory \\ e-mail: ganich1970@yandex.ru
}

Naumova Lyudmila Georgievna Cand. Agr. Sci.

Leading Research Associate of Ampelographic Laboratory e-mail: LGnaumova@yandex.ru

All-Russian Research

Institute named after Ya.I. Potapenko for Viticulture and Wine-making Branch of Federal State

Budget scientific Institution «Federal Rostov Agricultural Research Center», Novocherkassk, Russia

The purpose of the research is to study the introduced technical grapevine varieties of various ecological and geographical origin; to identify the adaptive, economic and technological potential of the samples in order to select genotypes with improved economically significant properties under the condition of the Lower Don Region. The study of the varieties was carried out in 2017-2019 at the Ya.I. Potapenko Don ampelographic collection (Novocherkassk), according to generally accepted methods and State Standards

\footnotetext{
* Работа выполнена при поддержке гранта РФФИ №18-016-00213.

* This work was supported by the RFBR grant No. 18-016-00213.
} 
проведённых исследований и наблюдений получены данные о протекании фенологических фаз, а также хозяйственно ценные показатели сортов (урожайность, средняя масса грозди, кондиции урожая и др.), дегустационные оценки вина. По количеству дней (от распускания почек до полной зрелости ягод) сорта были распределены по срокам созревания: от ранне-среднего до позднего. Очень высокая урожайность была у 7 сортов Адреули шави, Норок, Меграбуйр, Накутвнеули, Мерло, Ташкентский, Горули мцване. Средняя масса грозди у изучаемых сортов варьировала от 69 г (Муджуретули) до 502 г (Адреули шави). Отмечена очень высокая сахаристость сока ягод (более 23 г/100 $\mathrm{cm}^{3}$ ) у 8 сортов Бархатный, Мерло, Влеш, Амлаху, Рислинг мускатный, Муджуретули, Рубиновый Магарача, Димацкун. Высокие дегустационные оценки (проходной балл 8,2 ) получили сухие столовые вина из сортов Рислинг рейнский ( 8,8 балла), Рубиновый Магарача, Грубела, Каберне Совиньон (8,7 балла). Одиннадцать образцов оценены на уровне 8,6 балла. Вина из сортов Муджуретули, Амлаху, Меграбуйр, ВИР-1 получили 8,5 баллов. Из винограда сорта Бархатный приготовлено ликерное вино, которое получило оценку 8,7 балла. По комплексу агробиологических и хозяйственноценных признаков в условиях Нижнего Придонья выделились сорта: Рубиновый Магарача, Каберне Совиньон, Димацкун, Горули мцване, Накутвнеули, Норок, Рислинг мускатный, Мерло, Грдзелмтевана, Меграбуйр, Грубела и Ташкентский.

Ключевые слова: ВИНОГРАД, ИНТРОДУКЦИЯ, СОРТОИЗУЧЕНИЕ, УРОЖАЙНОСТЬ, СРОК СОЗРЕВАНИЯ, КОНДИЦИИ УРОЖАЯ, ДЕГУСТАЦИОННАЯ ОЦЕНКА ВИН in viticulture. Based on the results of research and observations, the data of phenological phases, economic and valuable indicators of varieties (yield, average mass of the bunch, crop conditions, etc.) are obtained, as well as wine tasting evaluations. According to the number of days (from budding to full maturity of berries), the varieties were ripening by maturation period: from early-middle to late period. Very high yield was in 7 varieties: Adreuli Shavi, Norok, Megrabuir, Nakutvneuli, Merlot, Tashkentskiy, Goruli Mtsvane. The average bunch weight of the studied varieties varied from $69 \mathrm{~g}$ (Mudjuretuli) to $502 \mathrm{~g}$ (Adreuli Shavi). It is noted a very high sugar content of berry juice (more than $23 \mathrm{~g} / 100 \mathrm{~cm}^{3}$ ) in 8 varieties Barhatniy, Merlot, Vlesh, Amlahu, Riesling Muscatniy, Mudjuretuli, Rubinoviy Magaracha, Dimatskun. Dry table wines from the following varieties received the high tasting ratings (a passing score of 8.2): Riesling Rhenskiy (8.8 points), Rubinoviy Magaracha, Grubela, Cabernet Sauvignon (8.7 points). Eleven samples were rated at 8.6 points. Wines from the Mudjuretuli, Amlahu, Megrabuir, VIR-1 received 8.5 points. A liqueur wine made from the Barhatniy grape variety received 8.7 points. The complex agrobiological and economically valuable characteristics under the conditions of the Lower Don Region we pointed out the varieties: Rubinoviy Magaracha, Cabernet Sauvignon, Dimackun, Goruli Mtsvane, Nakutvneuli, Norok, Riesling Muscatniy, Merlot, Grdzelmtebana, Megrabuir, Grubella and Tashkenskiy.

Key words: GRAPES, INTRODUCTION, VARIETY STUDY, YIELD CAPACITY, RIPENING PERIOD, CROP CONDITIONS, WINE TASTING EVALUATION 
Введение. В последние годы изучение генетических ресурсов находится в центре внимания мировой науки в связи с обеспечением продовольственной безопасности и является приоритетным направлением практически во всех странах мира не только на ближайшее, но и на отдалённое будущее [1-14]. Мобилизация сортовых ресурсов винограда в ампелографических коллекциях играет важную роль в сохранении, изучении и использовании генофонда винограда, так как существует реальная угроза потери значительного числа сортов в связи с исчезновением во многих регионах мира дикорастущего винограда, уменьшением количества сортов, реконструкцией старых насаждений и т.д. Большинство аборигенных и малораспространенных сортов в настоящее время сохранилось только благодаря коллекциям.

Наиболее ценными являются исследования растительных ресурсов винограда в одинаковых агроэкологических условиях. Для этого лучше всего подходят ампелографические коллекции, аккумулирующие на локальной территории с однородными агроэкологическими условиями большое разнообразие сортов различного видового, эколого-географического происхождения [15].

Донская ампелографическая коллекция имени Я.И. Потапенко выполняет фундаментальные и прикладные функции накопления и сохранения генофонда винограда, пополнения сортимента новыми классическими и интродуцированными сортами [16]. Для выполнения этих задач на коллекции ведутся научные исследования по сортоизучению, идентификации сортового состава, выделению источников хозяйственно ценных признаков, выявлению уровня адаптации к биотическим и абиотическим факторам среды [17].

Цель исследований - изучение интродуцированных технических сортов винограда различного эколого-географического происхождения; выявление адаптивного, хозяйственного и технологического потенциала образцов в целях отбора генотипов с улучшенными экономически значимыми свойствами в условиях Нижнего Придонья. 
Объекты и методы исследований. На Донской ампелографической коллекции имени Я.И. Потапенко в 2017-2019 гг. проведено изучение 23 интродуцированных технических сортов винограда. Сорта изучались в укрывной привитой культуре на подвое Берландиери х Рипариа Кобер 5ББ. Формировка кустов длиннорукавная. Схема посадки кустов 3,0 х 1,5 м. Культура неполивная.

Коллекция расположена на степном придонском плато. Высота местности над уровнем моря 90 м, рельеф волнистый. Почвы представлены обыкновенными карбонатными черноземами, среднемощными, слабо гумусированными, тяжелосуглинистыми на лессовидных суглинках, незасоленными, с высоким обеспечением фосфором, средним обеспечением подвижным калием, обогащены карбонатами кальция. Мощность гумусового горизонта достигает 90 см. Грунтовые воды залегают на глубине 15-20 м и для корней винограда недоступны.

Изучение сортов винограда проводили с использованием общепринятых в виноградарстве методик $[18,19]$. Сахаристость сока ягод определяли по ГОСТ 27198-87, титруемую кислотность по ГОСТ 32114-2013.

Обсужжение результатов. По данным фенологических наблюдений, распускание почек у изучаемых сортов проходило в период с 24 по 27 апреля, что соответствует средним многолетним данным (табл. 1). Начало цветения у большинства изучаемых сортов приходится на первую декаду июня. Продолжительность периода цветения составила 6 дней, с 30 мая по 4 июня. Ранний срок цветения отмечен у сортов Димацкун и Рубиновый Магарача (30 мая). Фаза созревания ягод оказывает существенное влияние на продолжительность вегетации растения и зависит от биологических особенностей сорта, места и условий произрастания, нагрузки кустов урожаем. По количеству дней от распускания почек до полной зрелости ягод сорта распределились: от ранне-среднего периода созревания (126-135 дней) до позднего (156-165 дней). 
Плодоводство и виноградарство Юга России № 64(4), 2020 г.

Таблица 1 - Прохождение фаз вегетации сортов винограда

\begin{tabular}{|c|c|c|c|c|c|c|}
\hline \multirow{2}{*}{ Сорт } & \multicolumn{4}{|c|}{ Дата начала фенофаз } & \multicolumn{2}{|c|}{$\begin{array}{c}\text { От распускания } \\
\text { почек до полной } \\
\text { зрелости ягод }\end{array}$} \\
\hline & $\begin{array}{c}\text { распускания } \\
\text { глазков }\end{array}$ & цветения & $\begin{array}{c}\text { созревания } \\
\text { ягод }\end{array}$ & $\begin{array}{c}\text { полная } \\
\text { зрелость } \\
\text { ягод }\end{array}$ & $\begin{array}{l}\text { число } \\
\text { дней }\end{array}$ & $\begin{array}{c}\text { сумма } \\
\text { температур } \\
{ }^{\circ} \mathrm{C}\end{array}$ \\
\hline \multicolumn{7}{|c|}{ Ранне-среднего периода созревания (126-135 дней) } \\
\hline Бархатный & 26.04 & 2.06 & 19.07 & 4.09 & 131 & 2965 \\
\hline Димацкун & 24.04 & 30.05 & 18.07 & 2.09 & 131 & 2935 \\
\hline Влеш & 27.04 & 4.06 & 23.07 & 6.09 & 132 & 3012 \\
\hline \multicolumn{7}{|c|}{ Среднего периода созревания (136-145 дней) } \\
\hline Грдзелмтевана & 25.04 & 31.05 & 26.06 & 9.09 & 137 & 3076 \\
\hline Налбандяни & 27.04 & 1.06 & 20.07 & 11.09 & 137 & 3060 \\
\hline Грубела & 26.04 & 2.06 & 1.08 & 12.09 & 139 & 3151 \\
\hline Муджуретули & 26.04 & 1.06 & 24.07 & 12.09 & 139 & 3145 \\
\hline Мерло & 27.04 & 1.06 & 28.07 & 14.09 & 140 & 3168 \\
\hline Рислинг мускатный & 26.04 & 1.06 & 26.07 & 13.09 & 140 & 3163 \\
\hline Пино нуар & 26.04 & 1.06 & 22.07 & 14.09 & 141 & 3166 \\
\hline Норок & 27.04 & 1.06 & 28.07 & 16.09 & 142 & 3207 \\
\hline Рислинг рейнский & 27.04 & 2.06 & 30.07 & 16.09 & 142 & 3215 \\
\hline Меграбуйр & 24.04 & 31.05 & 2.08 & 15.09 & 144 & 3239 \\
\hline \multicolumn{7}{|c|}{ Средне-позднего периода созревания (146-155 дней) } \\
\hline Амлаху & 25.04 & 1.06 & 29.07 & 20.09 & 148 & 3307 \\
\hline Горули мцване & 27.04 & 1.06 & 3.08 & 22.09 & 148 & 3322 \\
\hline Ташкентский & 25.04 & 31.05 & 20.07 & 20.09 & 148 & 3309 \\
\hline Каберне Совиньон & 26.04 & 31.05 & 30.07 & 22.09 & 149 & 3336 \\
\hline ВИР - 1 & 26.04 & 1.06 & 22.07 & 24.09 & 151 & 3377 \\
\hline Рубиновый Магарача & 26.04 & 30.05 & 29.07 & 25.09 & 152 & 3398 \\
\hline Накутвнеули & 25.04 & 2.06 & 31.07 & 25.09 & 153 & 3383 \\
\hline Вернахи & 27.04 & 2.06 & 10.08 & 29.09 & 155 & 3437 \\
\hline \multicolumn{7}{|c|}{ Позднего периода созревания (156-165 дней) } \\
\hline Арташати кармир & 26.04 & 1.06 & 22.07 & 28.09 & 156 & 3422 \\
\hline Адреули шави & 25.04 & 2.06 & 2.08 & 30.09 & 158 & 3453 \\
\hline
\end{tabular}

В условиях Нижнего Придонья представляют интерес сорта винограда ранне-среднего и среднего сроков созревания, так как сорта позднего срока созревания не всегда достигают технологической зрелости ягод. Такие сроки созревания отмечены у 13 изучаемых сортов.

Пригодность сорта для успешного выращивания в условиях произрастания определяется комплексом хозяйственно-биологических показателей и свойств [20]. Высокие проценты распустившихся почек и плодоносных побегов гарантируют получение стабильных урожаев винограда при возделывании в северной зоне промышленного виноградарства РФ. 
Плодоводство и виноградарство Юга России № 64(4), 2020 г.

По данным агробиологических учётов, в среднем за годы исследований, процент распустившихся глазков у изучаемых сортов винограда колебался от 68,6 у сорта Бархатный до 86,2 у сорта Ташкентский (табл. 2).

Таблица 2 - Хозяйственно ценные показатели изучаемых сортов винограда

\begin{tabular}{|c|c|c|c|c|c|c|}
\hline Сорт & $\begin{array}{c}\text { Распусти- } \\
\text { лось } \\
\text { глазков, } \\
\%\end{array}$ & $\begin{array}{c}\text { Плодо- } \\
\text { носных } \\
\text { побегов, } \\
\%\end{array}$ & $\begin{array}{c}\text { Коэффи- } \\
\text { циент } \\
\text { плодоно- } \\
\text { шения }\end{array}$ & $\begin{array}{c}\text { Средняя } \\
\text { масса } \\
\text { грозди, } \\
\text { г }\end{array}$ & $\begin{array}{c}\text { Продук- } \\
\text { тивность } \\
\text { побега, } \\
\text { г }\end{array}$ & $\begin{array}{c}\text { Расчетная } \\
\text { урожай- } \\
\text { ность, } \\
\text { т/га }\end{array}$ \\
\hline \multicolumn{7}{|c|}{ Урожайность очень высокая (17 т/га и более) } \\
\hline Адреули шави & 82,2 & 63,2 & 0,8 & 502 & 402 & 23,6 \\
\hline Норок & 81,1 & 79,2 & 1,5 & 195 & 293 & 22,8 \\
\hline Меграбуйр & 81,7 & 69,5 & 1,1 & 430 & 473 & 22,3 \\
\hline Накутвнеули & 72,7 & 78,0 & 1,3 & 233 & 303 & 21,0 \\
\hline Мерло & 73,0 & 80,4 & 1,4 & 193 & 270 & 20,1 \\
\hline Ташкентский & 86,2 & 57,1 & 0,9 & 217 & 195 & 17,7 \\
\hline Горули мцване & 76,3 & 75,5 & 1,2 & 293 & 352 & 17,2 \\
\hline \multicolumn{7}{|c|}{ Урожайность высокая (13-16 т/га) } \\
\hline $\begin{array}{l}\text { Рубиновый } \\
\text { Магарача }\end{array}$ & 78,2 & 86,1 & 1,6 & 151 & 242 & 16,3 \\
\hline Димацкун & 84,6 & 71,1 & 1,2 & 198 & 238 & 16,1 \\
\hline ВИР - 1 & 81,5 & 61,9 & 1,0 & 184 & 184 & 15,7 \\
\hline $\begin{array}{l}\text { Рислинг } \\
\text { мускатный }\end{array}$ & 79,6 & 87,8 & 1,7 & 146 & 248 & 15,3 \\
\hline Грдзелмтевана & 76,4 & 52,2 & 0,7 & 400 & 280 & 13,4 \\
\hline Каберне Совиньон & 77,4 & 84,7 & 1,5 & 106 & 159 & 12,9 \\
\hline Влеш & 82,9 & 53,6 & 0,9 & 254 & 229 & 12,6 \\
\hline Грубела & 75,4 & 36,9 & 0,4 & 464 & 186 & 12,5 \\
\hline Налбандяни & 70,9 & 52,4 & 0,8 & 276 & 221 & 12,4 \\
\hline \multicolumn{7}{|c|}{ Урожайность средняя (9-12 т/га) } \\
\hline Амлаху & 75,8 & 53,4 & 0,9 & 257 & 230 & 11,6 \\
\hline Вернахи & 71,8 & 70,0 & 1,0 & 245 & 245 & 11,5 \\
\hline Пино нуар & 78,7 & 72,0 & 1,2 & 125 & 150 & 10,5 \\
\hline Бархатный & 68,6 & 64,4 & 1,1 & 209 & 230 & 10,3 \\
\hline \multicolumn{7}{|c|}{ Урожайность низкая (5-8 т/га) } \\
\hline Рислинг рейнский & 68,9 & 72,0 & 1,2 & 93 & 112 & 6,4 \\
\hline \multicolumn{7}{|c|}{ Урожайность очень низкая (до 4 т/га) } \\
\hline Арташати кармир & 83,3 & 53,1 & 0,7 & 154 & 104 & 4,2 \\
\hline Муджуретули & 80,0 & 69,3 & 1,2 & 69 & 83 & 4,0 \\
\hline $\mathrm{HCP}$ & & & & 77,3 & & 10,2 \\
\hline
\end{tabular}

Процент плодоносных побегов у изучаемых сортов был от 52,2 (Грдзелмтевана) до 87,8 (Рислинг мускатный), исключение составил сорт Грубела, у него этот показатель был на уровне 36,9 \%. Высокие показатели коэффициента плодоношения отмечены у сортов: Рислинг мускатный $(1,7)$, 
Рубиновый Магарача $(1,6)$, Каберне Совиньон и Норок $(1,5)$; менее 1,0 у восьми изучаемых сортов, самый низкий он был у сорта Грубела $(0,4)$.

Важной особенностью сорта винограда является величина (масса) грозди, которая при применении определённой агротехники вместе с продуктивностью побега определяет, в основном, урожайность сорта. Средняя масса грозди варьировала от 69 г (Муджуретули) до 502 г (Адреули шави). Высокими показателями (более 400 г) выделились сорта Грубела, Меграбуйр, Грдзелмтевана. Наименьшая средняя масса грозди отмечена у сортов - Муджуретули, Рислинг рейнский и Каберне Совиньон.

По продуктивности побега выделены сорта Меграбуйр (473 г), Адреули шави (402 г), Горули мцване (352 г). У 16 изучаемых сортов продуктивность побегов была в диапазоне от 150 до 300 г. Самый низкий показатель продуктивности отмечен у сортов: Рислинг рейнский (112 г), Арташати кармир (104 г) и Муджуретули (83 г).

Важнейший хозяйственный признак - урожайность растений. Очень высокая и высокая расчетная урожайность отмечена у 16 изучаемых сортов: Адреули шави, Норок, Меграбуйр, Накутвнеули, Мерло, Рубиновый Магарача, Димацкун и др. Низкая урожайность была у сорта Рислинг рейнский, а очень низкая - у сортов Муджуретули и Арташати кармир.

Наряду с определением урожайности и продуктивности винограда не менее важной задачей сортоизучения является оценка качества урожая, позволяющая выяснить, в каком направлении выгоднее всего использовать сорт в природных и экономических условиях данного региона. Качество урожая зависит от наследственных факторов и условий выращивания. Основными показателями качества ягод винограда в период их созревания являются массовая концентрация сахаров и титруемых кислот в соке.

Проведя классификацию сортов по сахаристости отмечаем, что очень высокая сахаристость (более 23 г/100 см ${ }^{3}$ ) была у 8 сортов - Бархатный, Мерло, Влеш, Амлаху, Рислинг мускатный и др.; высокая сахаристость (21-23 г/100 см³) у 9 сортов - Меграбуйр, Горули мцване, Норок, Каберне 
Плодоводство и виноградарство Юга России № 64(4), 2020 г.

Совиньон, Пино нуар и др. Низкую сахаристость сока ягод (14-17 г/100 см³) имели два сорта - Адреули шави и Арташати кармир (табл. 3).

По показателям титруемой кислотности сорта распределились следующим образом: низкая титруемая кислотность (4-6 г/дм³) была у сортов Грубела и Налбандяни; высокая кислотность (1012 г/дм³ $)$ - у сортов Арташати кармир, Вернахи, Адреули шави и Рислинг мускатный; средняя (7-9 г/дм³ ) - у 17 сортов: Влеш, ВИР-1, Норок, Горули мцване, Мерло и др.

\section{Таблица 3 - Кондиции урожая изучаемых интродуцированных сортов винограда}

\begin{tabular}{|c|c|c|c|}
\hline \multirow[b]{2}{*}{ Сорт } & \multirow{2}{*}{$\begin{array}{c}\text { Дата } \\
\text { хим. анализа }\end{array}$} & \multicolumn{2}{|c|}{ Массовая концентрация } \\
\hline & & $\begin{array}{l}\text { сахаров, } \\
\Gamma / 100 \mathrm{~cm}^{3}\end{array}$ & $\begin{array}{c}\text { титруемых } \\
\text { кислот, г/дм }{ }^{3}\end{array}$ \\
\hline \multicolumn{4}{|c|}{ Очень высокая сахаристость сока ягод (более 23 г/100 см³) } \\
\hline Бархатный & 16.09 & 28,1 & 8,1 \\
\hline Мерло & 16.09 & 26,5 & 8,2 \\
\hline Влеш & 10.09 & 25,0 & 9,1 \\
\hline Амлаху & 26.09 & 24,8 & 7,5 \\
\hline Рислинг мускатный & 16.09 & 24,4 & 9,7 \\
\hline Муджуретули & 13.09 & 23,4 & 8,1 \\
\hline Рубиновый Магарача & 27.09 & 23,4 & 7,6 \\
\hline Димацкун & 03.09 & 23,3 & 7,6 \\
\hline \multicolumn{4}{|c|}{ Высокая сахаристость сока ягод $(21-23$ г/100 см³) } \\
\hline Меграбуйр & 16.09 & 22,9 & 6,9 \\
\hline Горули мцване & 25.09 & 22,8 & 7,6 \\
\hline Каберне Совиньон & 23.09 & 22,7 & 7,6 \\
\hline Норок & 20.09 & 22,7 & 8,4 \\
\hline Пино нуар & 19.09 & 22,7 & 7,4 \\
\hline Ташкентский & 19.09 & 22,5 & 7,1 \\
\hline Грдзелмтевана & 11.09 & 22,2 & 7,0 \\
\hline Накутвнеули & 23.09 & 21,5 & 8,1 \\
\hline ВИР - 1 & 23.09 & 21,3 & 8,5 \\
\hline \multicolumn{4}{|c|}{ Средняя сахаристость сока ягод $\left(18-20\right.$ г/100 см $\left.{ }^{3}\right)$} \\
\hline Рислинг рейнский & 16.09 & 20,4 & 7,7 \\
\hline Грубела & 14.09 & 20,3 & 5,8 \\
\hline Налбандяни & 7.09 & 18,6 & 6,1 \\
\hline Вернахи & 22.09 & 18,5 & 11,2 \\
\hline \multicolumn{4}{|c|}{ Низкая сахаристость сока ягод (14-17 г/100 см³) } \\
\hline Адреули шави & 23.09 & 17,6 & 10,8 \\
\hline Арташати кармир & 19.09 & 16,9 & 12,0 \\
\hline $\mathrm{HCP}$ & & 2,97 & 2,95 \\
\hline
\end{tabular}

Из изучаемых сортов винограда готовились образцы виноматериалов по классическим технологиям приготовления белых и красных вин [21]. 
Плодоводство и виноградарство Юга России № 64(4), 2020 г.

Высокие дегустационные оценки получили образцы вин из сортов: Рислинг рейнский - 8,8 балла, Рубиновый Магарача, Грубела, Каберне Совиньон - 8,7 балла. Одиннадцать образцов оценены на уровне 8,6 балла (Норок, Пино нуар, Горули мцване, Грдзелмтевана, Налбандяни, Мерло, Влеш, Рислинг мускатный, Димацкун, Ташкентский, Накутвнеули). Вина из сортов Муджуретули, Амлаху, Меграбуйр, ВИР-1 получили 8,5 баллов. Ликерное вино из винограда сорта Бархатный получило 8,7 балла.

Bbыводы. По комплексу агробиологических и хозяйственно ценных признаков (высокий процент распустившихся почек и плодоносных побегов, коэффициент плодоношения, средняя масса грозди, урожайность, оптимальное содержание сахаров и титруемых кислот в соке ягод, высокие дегустационные оценки вин) в условиях Нижнего Придонья выделились сорта винограда: Рубиновый Магарача, Каберне Совиньон, Димацкун, Горули мцване, Накутвнеули, Норок, Рислинг мускатный, Мерло, Грдзелмтевана, Меграбуйр, Грубела и Ташкентский. Данные сорта целесообразно возделывать в условиях Нижнего Придонья, а также их рекомендуется использовать в селекционных программах.

\section{Литература}

1. Фортов В.Е., Пальцев М.А. Генетические ресурсы растений, животных и микроорганизмов на службе человечества // Вестник российской академии наук. 2017. № 4(87). C. 375-376. DOI:10.7868/S0869587317040156.

2. Полулях А.А., Волынкин В.А., Лиховской В.В. Генетические ресурсы винограда института «Магарач». Проблемы и перспективы сохранения // Вавиловский журнал генетики и селекции. 2017. № 6(21). C. 608-616. DOI: 10.18699/VJ17.276.

3. Marrano A., Grzeskowiak L., Moreno Sanz P. et al. Genetic diversity and relationships in the grapevine germplasm collection from Central Asia // Vitis - Journal of Grapevine Research. 2015; 54: 233-237.

4. Failla O. East -West collaboration for grapevine diversity exploration and mobilization of adaptive traits for breeding: A four years story // Vitis - Journal of Grapevine Research. 2015; 54: 1-4.

5. Maletić E., Pejić I., Karoglan Kontić J. et al. Ampelographic and genetic characterization of Croatian grapevine varieties // Vitis - Journal of Grapevine Research. 2015; 54: 93-98.

6. Анапская ампелографическая коллекция - крупнейший центр аккумуляции и изучения генофонда винограда в России / М.И. Панкин, В.С. Петров [и др.] // Вавиловский журнал генетики и селекции. 2018. № 1(22). C. 54-59. DOI: 10.18699/VJ18.331. 
7. Новикова Л.Ю., Наумова Л.Г. Структурирование ампелографической коллекции по фенотипическим характеристикам и сравнение реакции сортов винограда на изменения климата // Вавиловский журнал генетики и селекции. 2019. № 6(23). C. 142-149. DOI:10.18699/VJ19.551.

8. Goryslavets S, Risovannaya V, Memetova E. et al. Genetic diversity of ancient grape cultivars of the Crimea region // Vitis - Journal of Grapevine Research. 2015; 54(1): 37-41.

9. Rustioni L., Maghradze D., Popescu C.F. et al. First results of the European grapevine collections' collaborative network: validation of a standard eno-carpological phenotyping method // Vitis. 2014; 53: 219-226.

10. Bitsadze N., Aznarashvili M., Vercesi A. et al. Screening of Georgian grapevine germplasm for susceptibility to downy mildew (Plasmopara viticola) // Vitis. 2015; 54: 193-196.

11. Изучение генетического сходства донских аборигенных сортов винограда с применением метода SSR-анализа и по основным ампелографическим признакам листа / Е.Т. Ильницкая [и др.] // Сельскохозяйственная биология. 2016. № 1(51). С. 60-67. DOI:10.15389/agrobiology. 2016.1.60rus.

12. Pelengic R., Koruza B. Slovenia grapevine germplasm // Acta Agriculturae Slovenica. 2012; 99(3):429-432.

13. Li S.H., Archbold D., London J. Collection, conservation, evaluation and utilization of Vitis amurensis germplasm resources in China // Acta Horticulturae. 2015; 1082: 79-86. DOI:10.17660/ActaHortic.2015.1082.10

14. Maul E., Töpfer R., Carka F. et al. Identification and characterization of grapevine genetic resources maintained in Eastern European Collections // Vitis. 2015;54:5-12.

15. Петров В. С., Панкин М. И., Коваленко А. Г. Агробиологические свойства технических сортов винограда в условиях умеренно-континентального климата юга России [Электронный ресурс] // Плодоводство и виноградарство Юга России. 2018. № 49(1). C. 1-15. URL: http://journalkubansad.ru/pdf/18/01/01.pdf. (дата обращения: 01.07.2020).

16. Ганич В.А., Наумова Л.Г., Матвеева Н.В. Перспективы использования красных межвидовых гибридов для качественного виноделия // Русский виноград. 2019. T. 9. C. 6-12. DOI:10.32904/2412-9836-2019-9-6-12.

17. Ганич В.А., Наумова Л.Г., Матвеева Н.В. Агробиологическая и технологическая оценка сортов винограда селекции института «Магарач» на ампелографической коллекции ВНИИВиВ им. Я.И. Потапенко // Магарач. Виноградарство и виноделие. 2018. № 2(104). С. 28-30.

18. Лазаревский М.А. Изучение сортов винограда. Ростов-на-Дону: Изд-во Ростовского университета, 1963, 151 с.

19. Амирджанов А.Г., Сулейманов Д.С. Оценка продуктивности сортов винограда и виноградников: Методические указания. Баку, 1986, 54 с.

20. Полулях А.А., Волынкин В.А. Мировая ампелографическая коллекция Национального института винограда и вина «Магарач» // Виноградарство и виноделие: Сб. науч. тр. НИВиВ «Магарач». 2014. T. XLIV. C. 5-8.

21. Сборник технологических инструкций, правил и нормативных материалов по винодельческой промышленности / под ред. Г.Г. Валуйко. М.: Агропромиздат, 1985, 511 с.

\section{References}

1. Fortov V.E., Pal'cev M.A. Geneticheskie resursy rastenij, zhivotnyh i mikroorganizmov na sluzhbe chelovechestva // Vestnik rossijskoj akademii nauk. 2017. № 4(87). S. 375-376. DOI:10.7868/S0869587317040156.

2. Polulyah A.A., Volynkin V.A., Lihovskoj V.V. Geneticheskie resursy vinograda instituta «Magarach». Problemy i perspektivy sohraneniya // Vavilovskij zhurnal genetiki i selekcii. 2017. № 6(21). S. 608-616. DOI: 10.18699/VJ17.276. 
3. Marrano A., Grzeskowiak L., Moreno Sanz P. et al. Genetic diversity and relationships in the grapevine germplasm collection from Central Asia // Vitis - Journal of Grapevine Research. 2015; 54: 233-237.

4. Failla O. East -West collaboration for grapevine diversity exploration and mobilization of adaptive traits for breeding: A four years story // Vitis - Journal of Grapevine Research. 2015; 54: 1-4.

5. Maletić E., Pejić I., Karoglan Kontić J. et al. Ampelographic and genetic characterization of Croatian grapevine varieties // Vitis - Journal of Grapevine Research. 2015; 54: 93-98.

6. Anapskaya ampelograficheskaya kollekciya - krupnejshij centr akkumulyacii i izucheniya genofonda vinograda v Rossii / M.I. Pankin, V.S. Petrov [i dr.] // Vavilovskij zhurnal genetiki i selekcii. 2018. № 1(22). S. 54-59. DOI: 10.18699/VJ18.331.

7. Novikova L.Yu., Naumova L.G. Strukturirovanie ampelograficheskoj kollekcii po fenotipicheskim harakteristikam i sravnenie reakcii sortov vinograda na izmeneniya klimata // Vavilovskij zhurnal genetiki i selekcii. 2019. № 6(23). S. 142-149. DOI:10.18699/VJ19.551.

8. Goryslavets S, Risovannaya V, Memetova E. et al. Genetic diversity of ancient grape cultivars of the Crimea region // Vitis - Journal of Grapevine Research. 2015; 54(1): 37-41.

9. Rustioni L., Maghradze D., Popescu C.F. et al. First results of the European grapevine collectionsl' collaborative network: validation of a standard eno-carpological phenotyping method // Vitis. 2014; 53: 219-226.

10. Bitsadze N., Aznarashvili M., Vercesi A. et al. Screening of Georgian grapevine germplasm for susceptibility to downy mildew (Plasmopara viticola) // Vitis. 2015; 54: 193-196.

11. Izuchenie geneticheskogo skhodstva donskih aborigennyh sortov vinograda $\mathrm{s}$ primeneniem metoda SSR-analiza i po osnovnym ampelograficheskim priznakam lista / E.T. Il'nickaya [i $\mathrm{d}$ dr.] // Sel'skohozyajstvennaya biologiya. 2016. № 1(51). S. 60-67. DOI:10.15389/agrobiology. 2016.1.60rus.

12. Pelengic R., Koruza B. Slovenia grapevine germplasm // Acta Agriculturae Slovenica. 2012; 99(3):429-432.

13. Li S.H., Archbold D., London J. Collection, conservation, evaluation and utilization of Vitis amurensis germplasm resources in China // Acta Horticulturae. 2015; 1082: 7986. DOI:10.17660/ActaHortic.2015.1082.10

14. Maul E., Töpfer R., Carka F. et al. Identification and characterization of grapevine genetic resources maintained in Eastern European Collections // Vitis. 2015;54:5-12.

15. Petrov V. S., Pankin M. I., Kovalenko A. G. Agrobiologicheskie svojstva tekhnicheskih sortov vinograda $\mathrm{v}$ usloviyah umerenno-kontinental'nogo klimata yuga Rossii [Elektronnyj resurs] // Plodovodstvo i vinogradarstvo Yuga Rossii. 2018. № 49(1). S. 1-15. URL: http://journalkubansad.ru/pdf/18/01/01.pdf. (data obrashcheniya: 01.07.2020).

16. Ganich V.A., Naumova L.G., Matveeva N.V. Perspektivy ispol'zovaniya krasnyh mezhvidovyh gibridov dlya kachestvennogo vinodeliya // Russkij vinograd. 2019. T. 9. S. 6-12. DOI:10.32904/2412-9836-2019-9-6-12.

17. Ganich V.A., Naumova L.G., Matveeva N.V. Agrobiologicheskaya i tekhnologicheskaya ocenka sortov vinograda selekcii instituta «Magarach» na ampelograficheskoj kollekcii VNIIViV im. Ya.I. Potapenko // Magarach. Vinogradarstvo i vinodelie. 2018. № 2(104). S. 28-30.

18. Lazarevskij M.A. Izuchenie sortov vinograda. Rostov-na-Donu: Izd-vo Rostovskogo universiteta, 1963, $151 \mathrm{~s}$.

19. Amirdzhanov A.G., Sulejmanov D.S. Ocenka produktivnosti sortov vinograda i vinogradnikov: Metodicheskie ukazaniya. Baku, 1986, $54 \mathrm{s.}$

20. Polulyah A.A., Volynkin V.A. Mirovaya ampelograficheskaya kollekciya Nacional'nogo instituta vinograda i vina «Magarach» // Vinogradarstvo i vinodelie: Sb. nauch. tr. NIViV «Magarach». 2014. T. XLIV. S. 5-8.

21. Sbornik tekhnologicheskih instrukcij, pravil i normativnyh materialov po vinodel'cheskoj promyshlennosti / pod red. G.G. Valujko. M.: Agropromizdat, 1985, 511 s. 